\title{
Lipid Targets in Clinical Practice: Successes, Failures and Lessons to be Learned
}

\author{
M Dunne \\ Tallaght Hospital \\ Oscar Mac Ananey \\ Technological University Dublin, oscar.macananey@tudublin.ie \\ V Maher \\ Tallaght Hospital
}

Follow this and additional works at: https://arrow.tudublin.ie/scschbioart

Part of the Cardiology Commons, Endocrinology, Diabetes, and Metabolism Commons, and the Medical Physiology Commons

\section{Recommended Citation}

Dunne, M., Mac Ananey, O. and Maher, V. (2013) Lipid targets in clinical practice: successes, failures and lessons to be learned. Irish Journal Medical Sciences, December 2013, Volume 182, Issue 4, pp 673-678. doi:10.1007/s11845-013-0954-6

This Article is brought to you for free and open access by the School of Biological Sciences at ARROW@TU Dublin. It has been accepted for inclusion in Articles by an authorized administrator of ARROW@TU Dublin. For more information, please contact arrow.admin@tudublin.ie, aisling.coyne@tudublin.ie,gerard.connolly@tudublin.ie.

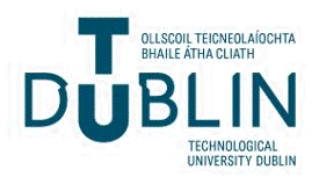




\title{
2 Lipid targets in clinical practice: successes, failures and lessons 3 to be learned
}

\author{
4 M. Dunne - O. M. Ananey - C. Markham • \\ 5 V. Maher
}

6 Received: 17 August 2012/ Accepted: 11 April 2013

7 C) Royal Academy of Medicine in Ireland 2013

\section{Abstract} control.
Introduction Optimal risk factor control is integral to managing patients with proven coronary heart disease $(\mathrm{CHD}+)$ and for those at risk of coronary heart disease (CHD-). The primary aim of the study was to assess the success rate of reaching lipid risk factor targets in a multiple risk factor clinic.

Methods A retrospective audit was conducted in 488 patients (CHD+, $n=112$; CHD-, $n=376$ ) who attended the Cardiovascular Risk Factor Clinic at Tallaght Hospital, Dublin in 2009 and 2010.

Results Risk factor targets achieved in $\mathrm{CHD}+$ and CHD- patients were LDLc (54/62 \%), HDLc (67/67 \%), systolic blood pressure $(35 / 38 \%)$, diastolic blood pressure $(82 / 75 \%)$, smoking cessation $(27 / 26 \%), \mathrm{BMI} \leq 30$ (39/ $50 \%)$ and normal waist circumference $(27 / 39 \%)$. Patients not reaching LDLc targets were found to be receiving fewer lipid-lowering drugs and having higher LDL levels at the initial clinic visit than those reaching targets.

Discussion This retrospective audit highlights gaps in achieving target lipid levels at a multiple risk factor clinic level. High initial LDLc levels and lack of drug titration are evident. Guideline changes, staff rotation, clinic visit frequency and multiplicity of targets may be contributory. More emphasis needs to be placed on education and algorithm-based strategies to achieve better risk factor

Keywords Risk factor audit - Lipid targets . Cardiovascular risk factors - Coronary heart disease . Obesity · Blood pressure

M. Dunne · O. M. Ananey · C. Markham · V. Maher ( $\square)$

Tallaght Hospital, Dublin, Co Dublin, Ireland

e-mail: vmaher@gmail.com

\section{Introduction}

Coronary heart disease (CHD) is a major cause of morbidity and mortality in the developed world. Many risk factors have been identified which have a strong association with CHD, such as raised low-density lipoprotein cholesterol levels (LDLc), reduced high-density lipoprotein cholesterol levels (HDLc), hypertension, diabetes, smoking and increased waist circumference [1-5]. Treating these risk factors is critical to reducing the burden of CHD. While controlled drug trials have yielded significant risk factor improvements resulting in reduced cardiovascular events, such successes are not equally matched in clinical practice [6]. Assessing risk factor modification in clinical practice may therefore help identify where problem areas exist. Exploring these areas and identifying their associations may be important in achieving better risk factor control.

Our aim was therefore to perform a retrospective audit of our risk factor clinic to identify how well risk factors were being controlled and examine if any patterns exist that might guide future interventions.

\section{Methods}

The management of CHD and its associated risk factors was assessed by a retrospective audit of patients $(n=488)$ attending the Cardiovascular Risk Factor Clinic at Tallaght Hospital in 2009 and 2010.

Patients were referred, with or without pre-existing heart disease, to the clinic from their local G.P., other hospital services or the occupational health department at their place of work. The audit did not require ethical approval.

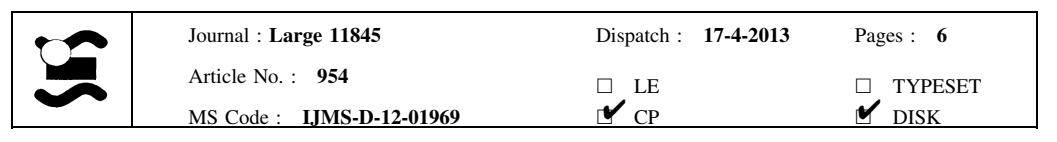


CHD risk factors, including hypertension, abnormal blood lipid profile, hyperglycemia, BMI and smoking were recorded from each patient's initial clinic visit (Initial) and most recent (Latest) visits to the clinic (mean $\pm \mathrm{SD}$ : $35 \pm 31$ months). In addition to the major cardiovascular risk factors, age, gender, medication, family history and waist circumference were also recorded. LDLc values were calculated using the Friedewald formula [7] (LDLc $=$ total cholesterol - (triglyceride/2.12 + HDLc)) and only used if triglyceride levels were $<4 \mathrm{mmol} / \mathrm{l}$. The values for 12 patients could not be calculated because of triglyceride values $>4 \mathrm{mmol} / \mathrm{l}$. Patients were subdivided into those with coronary heart disease (CHD,$+ n=112)$ and those without coronary heart disease (CHD,$- n=376$ ).

Unpaired $t$ test and Fisher's exact test were used to detect the absolute and relative differences between the CHD+ and CHD - groups (JMP Version 4.0, SAS Institute Inc., NC, USA). Data are presented as mean \pm SD unless otherwise stated.

\section{Results}

The average time interval between baseline and final visits was $35 \pm 31$ months with $77 \%$ of patients attending the clinic for at least 1 year.

The risk factor levels of all patients at the initial visit are outlined in Table 1 . The CHD+ group was significantly older and received greater lipid-lowering therapies compared to the CHD - group $(p<0.0001)$. The mean total cholesterol, LDLc and HDLc levels (males) were significantly lower in the CHD+ group compared to the CHDgroup $(p<0.0001)$. The presence of diabetes and stroke was significantly higher in the CHD+ group. While mean diastolic blood pressures were significantly lower in the $\mathrm{CHD}+$ group, there was no significant difference in the percentage of patients with a history of hypertension or clinic-measured systolic blood pressures between the groups. Smoking status, waist circumference and BMI were not different between groups.

The impact of intervention in both groups attending the risk factor clinic is outlined in Table 2 where comparison of initial and latest clinic visits can be seen. Since targets for LDLc changed during the period of audit, both new and old target levels are included. There was a significant increase in the percentage of patients in both groups receiving lipid-lowering therapy at their latest clinic visit, which was particularly evident in the CHD- group who had $<40 \%$ lipid-lowering treatments at their initial visit.

$90 \%$ of patients taking lipid-lowering medication were receiving statin monotherapy. $50 \%$ of patients were prescribed atorvastatin $(10 \mathrm{mg} 32 \%, 20 \mathrm{mg} 27 \%, 40 \mathrm{mg}$ $27 \%$ and $14 \%$ dose not documented), $24 \%$ were
Table 1 Baseline risk factor levels at initial clinic presentation according to CHD status

\begin{tabular}{|c|c|c|c|}
\hline \multirow[t]{2}{*}{ Risk variable } & \multirow{2}{*}{$\frac{\mathrm{CHD}+}{n=112}$} & \multirow{2}{*}{$\begin{array}{l}\text { CHD- } \\
n=376\end{array}$} & \multirow[t]{2}{*}{$p$} \\
\hline & & & \\
\hline Age (years) & $59 \pm 11$ & $51 \pm 12$ & $<0.0001$ \\
\hline On lipid Tx & $73 \%$ & $39 \%$ & $<0.0001$ \\
\hline Total cholesterol (mmol/L) & $4.8 \pm 1.2$ & $5.5 \pm 1.3$ & $<0.0001$ \\
\hline $\mathrm{LDL}(\mathrm{mmol} / \mathrm{L})$ & $2.7 \pm 1.1$ & $3.2 \pm 1.1$ & $<0.0001$ \\
\hline HDL male $(\mathrm{mmol} / \mathrm{L})$ & $1.2 \pm 0.3$ & $1.3 \pm 0.4$ & $<0.05$ \\
\hline HDL female (mmol/L) & $1.5 \pm 0.3$ & $1.6 \pm 0.4$ & NS \\
\hline Triglyceride (mmol/L) & $1.9 \pm 1.1$ & $2.1 \pm 2.4$ & NS \\
\hline Hypertension history & $43 \%$ & $41 \%$ & NS \\
\hline Systolic BP (mmHg) & $139 \pm 20$ & $142 \pm 23$ & NS \\
\hline Diastolic BP (mmHg) & $82 \pm 14$ & $85 \pm 15$ & $<0.05$ \\
\hline \multicolumn{4}{|l|}{ Smoking status } \\
\hline Yes & $23 \%$ & $31 \%$ & NS \\
\hline No & $77 \%$ & $69 \%$ & NS \\
\hline Diabetes history & $14 \%$ & $6 \%$ & $<0.05$ \\
\hline Glucose (mmol/L) & $5.9 \pm 1.6$ & $5.3 \pm 0.7$ & $<0.01$ \\
\hline BMI $\left(\mathrm{kg} / \mathrm{m}^{2}\right)$ & $31.1 \pm 4.9$ & $31.0 \pm 6.1$ & NS \\
\hline WC male $(\mathrm{cm})$ & $102.1 \pm 11.4$ & $102.7 \pm 13.5$ & NS \\
\hline WC female $(\mathrm{cm})$ & $97.3 \pm 1.3$ & $95.4 \pm 1.3$ & NS \\
\hline History of CVA & $10 \%$ & $4 \%$ & $<0.05$ \\
\hline History of PVD & $4 \%$ & $2 \%$ & NS \\
\hline
\end{tabular}

Unpaired $t$ test and Fisher's exact test were used to detect absolute and relative differences between CHD+ and CHD- groups. Data are mean \pm SD unless otherwise stated

$L D L c$ low-density lipoprotein cholesterol, HDLc high-density lipoprotein cholesterol, $B P$ blood pressure, $B M I$ body mass index, $W C$ waist circumference, $C V A$ cerebrovascular accident, $P V D$ peripheral vascular disease.

prescribed rosuvastatin $(10 \mathrm{mg} 55 \%, 20 \mathrm{mg} 29 \%, 40 \mathrm{mg}$ $9 \%$ and $7 \%$ dose not documented), $10 \%$ were prescribed pravastatin (10 mg $18 \%, 20 \mathrm{mg} 39 \%, 40 \mathrm{mg} 36 \%$ and $7 \%$ dose not documented) and $7 \%$ were prescribed simvastatin $(20 \mathrm{mg} 44 \%, 40 \mathrm{mg} 20 \%$ and $36 \%$ dose not documented). The remaining $9 \%$ of patients were taking other lipid therapies.

There was a significant increase in the number of CHDand CHD+ patients reaching LDLc target levels $(p<0.01)$ when the old LDLc target of $<3.0 \mathrm{mmol} / \mathrm{l}$ was used, but no differences were observed when new target levels $(<2.5 \mathrm{mmol} / \mathrm{L})$ were used.

The percentage of patients achieving HDL targets was unchanged from initial to latest visits. The percentage reaching systolic blood pressure targets levels was unchanged, whereas the percentage of patients reaching diastolic blood pressure targets $(<85 \mathrm{mmHg})$ significantly improved in both groups of patients. The percentage of nonsmokers increased in both patient groups, but this only reached significance in the CHD- group. The percentage 
Table 2 Number and percent of patients reaching risk factor targets for initial and latest visits according to the CHD status

\begin{tabular}{|c|c|c|c|c|c|c|}
\hline \multirow[t]{2}{*}{ Targets } & \multicolumn{3}{|l|}{$\mathrm{CHD}+$} & \multicolumn{3}{|l|}{ CHD- } \\
\hline & Initial & Latest & $p$ & Initial & Latest & $p$ \\
\hline On lipid Tx & $73 \%$ & $87 \%$ & $<0.05$ & $39 \%$ & $68 \%$ & $<0.0001$ \\
\hline New LDL target & $42(42 \%)$ & $54(54 \%)$ & NS & $* 140(43 \%)$ & *204 (62 \%) & $<0.0001$ \\
\hline Old LDL target & $63(63 \%)$ & $81(81 \%)$ & $<0.01$ & $* 140(43 \%)$ & *204 (62 \%) & \\
\hline $\mathrm{HDL} \geq 1.0 \mathrm{M} \geq 1.3 \mathrm{~F}$ & $83(74 \%)$ & $75(67 \%)$ & NS & $261(71 \%)$ & $247(67 \%)$ & NS \\
\hline Sys BP $<130$ & $49(44 \%)$ & $40(35 \%)$ & NS & $136(36 \%)$ & $143(38 \%)$ & NS \\
\hline Dia $\mathrm{BP}<85$ & $71(64 \%)$ & $91(82 \%)$ & $<0.01$ & $211(56 \%)$ & $281(75 \%)$ & $<0.0001$ \\
\hline Nonsmokers & $86(77 \%)$ & $93(83 \%)$ & NS & $260(69 \%)$ & $290(77 \%)$ & $<0.05$ \\
\hline $\mathrm{BMI} \leq 30$ & $59(53 \%)$ & $44(39 \%)$ & $<0.05$ & $186(50 \%)$ & $188(50 \%)$ & NS \\
\hline $\mathrm{WC}<102 \mathrm{M}<88 \mathrm{~F}$ & $38(43 \%)$ & $24(27 \%)$ & $<0.05$ & $128(41 \%)$ & $122(39 \%)$ & NS \\
\hline Glucose $<6.2$ & $28(80 \%)$ & $24(69 \%)$ & NS & $88(84 \%)$ & $85(81 \%)$ & NS \\
\hline
\end{tabular}

LDLc data for 12 patients could not be calculated (Friedewald) because of high triglyceride values. Unpaired $t$ test and Fisher's exact test were used to detect absolute and relative differences between the initial and final visits

$L D L c$ low-density lipoprotein cholesterol (new LDLc target based on $<2.5$ for CHD + and $<3.0$ for CHD-, old LDLc target $<3.0$ for CHD+). $H D L c$ high-density lipoprotein cholesterol, Sys BP systolic blood pressure, Dia BP diastolic blood pressure, BMI body mass index, WC waist circumference, $M$ male, $F$ female

* New and old LDLc targets remain unchanged for patients without CHD

140 of patients in the CHD- group who achieved BMI and 141 waist circumference target levels was unchanged. How142 ever, the percentage of patients in the CHD+ group who 143 achieved BMI and waist circumference target levels was 144 significantly reduced compared to the initial clinic visits.

The factors associated with achieving or not achieving LDLc targets in both groups are outlined in Table 3. The only notable factor in the CHD+ group was that those reaching LDLc targets had also a significantly greater increase in HDLc levels. In contrast, in the CHD- group, those achieving LDLc target levels were older, male, had lower baseline LDLc levels and were on lipid-lowering medication. Reaching LDLc targets did not relate to weight changes.

Table 4 outlines the factors associated with reaching HDLc targets in both groups. Patients in the CHD+ group achieving HDLc targets were older, had higher HDLc levels initially and were on less lipid-lowering drugs when initially reviewed.

In the CHD- group, the patients reaching HDLc targets had significantly higher baseline HDLc levels and there was a greater proportion of males than females. There was also a significantly greater reduction in systolic blood pressure in those reaching HDLc targets.

\section{Discussion}

This retrospective audit gives some insight into how cardiovascular risk factors are being managed in clinical practice. Given the high risk population involved, it is noteworthy that $87 \%$ of patients with proven CHD were on lipid-lowering therapy and over $80 \%$ had achieved LDLc levels $<3.00 \mathrm{mmol} / \mathrm{L}$ with $54 \%$ achieving LDLc levels below $2.50 \mathrm{mmol} / \mathrm{l}$. These findings are not as good as previous studies where 73 and $79 \%$ of patients achieved target LDLc levels $(<2.50 \mathrm{mmol} / \mathrm{L})[8,9]$. However it must be noted that patient data recorded for the present study was based on older LDLc guidelines $(<3.00 \mathrm{mmol} / \mathrm{L})$.

LDLc target achievement was similar to that observed in the EUROASPIRE studies where $\sim 54 \%$ of patients achieved target total cholesterol $(<4.5 \mathrm{mmol} / \mathrm{L})$ [10].

Statin therapies were either not started or not uptitrated in $77 \%$ of CHD - and $80 \%$ of CHD+ despite patients failing to achieve LDLc targets. Previous research also reports that in the majority of patients, statin doses remain unchanged regardless of improvements, or lack thereof, in LDLc control. [10] In the current study, $57 \%$ of CHD+ patients who were uptitrated achieved LDLc targets. This further emphasizes the need for clinicians to constantly review and uptitrate medication where possible.

Age, gender, weight changes, blood pressure changes, percent on lipid-lowering treatment and drug doses were not influencing factors in reaching target LDLc levels in those with CHD. In patients without CHD, it is not surprising that factors such as age, male gender and initial LDLc levels were the significant factors associated with reaching targets as they would all be considered reasons to treat. Overall, the main explanation why some patients reached targets whereas others did not appeared to be better response to treatment as judged by the greater LDLc reductions and HDLc increases. $77 \%$ of 
Table 3 Factors affecting the achievement of LDLc targets at the latest visit

\begin{tabular}{|c|c|c|c|c|c|c|}
\hline & \multicolumn{6}{|c|}{ LDL targets } \\
\hline & \multicolumn{2}{|l|}{$\mathrm{CHD}+$} & \multirow[t]{2}{*}{$p$} & \multicolumn{2}{|l|}{ CHD- } & \multirow[t]{2}{*}{$p$} \\
\hline & $\begin{array}{l}\text { Reached } \\
n=57\end{array}$ & $\begin{array}{l}\text { Not reached } \\
n=48\end{array}$ & & $\begin{array}{l}\text { Reached } \\
n=226\end{array}$ & $\begin{array}{l}\text { Not reached } \\
n=136\end{array}$ & \\
\hline Age (years) & $62 \pm 10$ & $65 \pm 10$ & NS & $55 \pm 12$ & $51 \pm 13$ & $<0.01$ \\
\hline Gender M:F & $39: 18$ & $25: 23$ & NS & $111: 115$ & $48: 88$ & $<0.05$ \\
\hline Initial LDL (mmol/L) & $2.5 \pm 1.2$ & $3 \pm 0.9$ & NS & $3.0 \pm 1.0$ & $3.6 \pm 1.2$ & $<0.0001$ \\
\hline LDLc $\Delta$ & $-14.5 \%$ & $8.8 \%$ & $<0.01$ & $-19.0 \%$ & $10.8 \%$ & $<0.0001$ \\
\hline HDLc $\Delta$ & $8.9 \%$ & $-3.1 \%$ & $<0.05$ & $-2.1 \%$ & $0.3 \%$ & NS \\
\hline $\operatorname{SBP} \Delta$ & $0.2 \%$ & $-1.0 \%$ & NS & $-2.6 \%$ & $-1.3 \%$ & NS \\
\hline DBP $\Delta$ & $-3.5 \%$ & $-3.3 \%$ & NS & $-4.6 \%$ & $-5.9 \%$ & NS \\
\hline BMI $\Delta$ & $1.7 \%$ & $1.1 \%$ & NS & $1.2 \%$ & $1.8 \%$ & NS \\
\hline WC $\Delta$ & $3.3 \%$ & $4.6 \%$ & NS & $2.2 \%$ & $1.6 \%$ & NS \\
\hline On lipid Tx initial & $74 \%$ & $69 \%$ & NS & $45 \%$ & $29 \%$ & $<0.01$ \\
\hline On lipid Tx latest & $92 \%$ & $79 \%$ & NS & $77 \%$ & $51 \%$ & $<0.0001$ \\
\hline
\end{tabular}

$L D L c$ low-density lipoprotein cholesterol, $H D L c$ high-density lipoprotein cholesterol, $S B P$ systolic blood pressure, $D B P$ diastolic blood pressure. $B M I$ body mass index, $W C$ waist circumference. $M$ male, $F$ female, $\Delta$ mean percent change in risk factor from the initial visit to the latest visit. Unpaired $t$ test and Fisher's exact test were used to detect absolute and relative differences between the initial and latest visits. Data are mean \pm SD unless otherwise stated. LDLc data for 12 patients could not be calculated because of high triglyceride levels

Table 4 Factors affecting the achievement of HDLc targets at the latest visit

\begin{tabular}{|c|c|c|c|c|c|c|}
\hline & \multicolumn{6}{|c|}{ HDL targets } \\
\hline & \multicolumn{2}{|l|}{$\mathrm{CHD}+$} & \multirow[t]{2}{*}{$p$} & \multicolumn{2}{|l|}{ CHD- } & \multirow[t]{2}{*}{$p$} \\
\hline & $\begin{array}{l}\text { Reached } \\
n=73\end{array}$ & $\begin{array}{l}\text { Not reached } \\
n=32\end{array}$ & & $\begin{array}{l}\text { Reached } \\
n=252\end{array}$ & $\begin{array}{l}\text { Not reached } \\
n=110\end{array}$ & \\
\hline Age (years) & $65 \pm 10$ & $59 \pm 9$ & $<0.01$ & $54 \pm 12$ & $52 \pm 13$ & NS \\
\hline Gender M:F & $43: 30$ & $21: 11$ & NS & $124: 128$ & $35: 75$ & $<0.01$ \\
\hline Initial HDL (mmol/L) & $1.4 \pm 0.3$ & $1.1 \pm 0.3$ & $<0.0001$ & $1.6 \pm 0.4$ & $1.2 \pm 0.3$ & $<0.0001$ \\
\hline HDLc $\Delta$ & $7.1 \%$ & $-6.1 \%$ & $<0.05$ & $2.1 \%$ & $-9.4 \%$ & $<0.0001$ \\
\hline LDLc $\Delta$ & $-4.8 \%$ & $-1.5 \%$ & NS & $-7.5 \%$ & $-8.4 \%$ & NS \\
\hline SBP $\Delta$ & $-1.4 \%$ & $2.0 \%$ & NS & $-3.2 \%$ & $0.4 \%$ & $<0.05$ \\
\hline $\mathrm{DBP} \Delta$ & $-4.8 \%$ & $-0.3 \%$ & NS & $-5.9 \%$ & $-3.3 \%$ & NS \\
\hline BMI $\Delta$ & $1.3 \%$ & $1.8 \%$ & NS & $1.7 \%$ & $0.8 \%$ & NS \\
\hline WC $\Delta$ & $3.1 \%$ & $5.6 \%$ & NS & $2.2 \%$ & $1.3 \%$ & NS \\
\hline On lipid Tx initial & $64 \%$ & $88 \%$ & $<0.05$ & $38 \%$ & $41 \%$ & NS \\
\hline On lipid Tx latest & $74 \%$ & $78 \%$ & NS & $71 \%$ & $73 \%$ & NS \\
\hline
\end{tabular}

$H D L c$ high-density lipoprotein cholesterol, $L D L c$ low-density lipoprotein cholesterol, $S B P$ systolic blood pressure, $D B P$ diastolic blood pressure. $B M I$ body mass index, $W C$ waist circumference, $M$ male, $F$ female, $\Delta$ mean percent change in risk factor from the initial visit to the latest visit. Unpaired $t$ test and Fisher's exact test were used to detect absolute and relative differences between groups that reached and did not reach HDLc targets. Data are mean \pm SD unless otherwise stated

199 patients attended the clinic for $>1$ year with an average

of four to five visits per patient. This should have given ample time for lipid-lowering therapies and lifestyle modifications to take effect. There were no differences in the relative number of patients reaching LDLc targets who attended for less than 12 months. Therefore, it is unlikely that the duration of clinic attendance impacted on the results.
It is also noteworthy that many patients were referred to this clinic due to refractoriness to treatment, drug intolerances and having co-morbidities such as liver and renal disease which may limit aggressive treatment. In addition, since this is a multiple risk factor clinic, success at achieving some risk factor targets such as smoking cessation and blood pressure control may have influenced the aggressiveness of lipid-lowering strategies. As patients

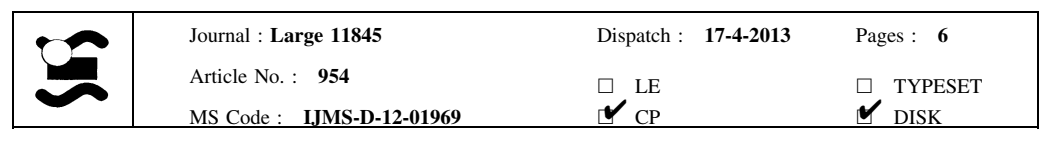


attend the clinic usually on a 6-monthly or annual basis due to limited clinic places, focus on one particular risk factor may have been emphasized more than others.

HDLc is gaining increasing importance as an independent cardiovascular risk factor and predictor for cardiovascular risk [11]. Its levels may improve using statin therapy [12]. However, its manipulation to reduce cardiovascular events is being questioned [13]. According to the guidelines set out by European Society of Cardiology, HDL levels should be $>1.0 \mathrm{mmol} / \mathrm{L}(40 \mathrm{mg} / \mathrm{dL})$ in males and $>1.2 \mathrm{mmol} / \mathrm{L}(46 \mathrm{mg} / \mathrm{dL})$ in females. In the present study, approximately two-thirds of patients in the clinic had HDLc target levels at baseline. There was no significant change during clinic visits.

This reflects the high baseline levels and that statin therapy, while having some beneficial effects on HDLc, is insufficient to appropriately manage low HDLc levels [14]. Intensive lifestyle modification in conjunction with niacin and fibrate intervention may improve HDLc status and therefore improve risk factor status in patients with dyslipidemia $[10,11]$. Such strategies need better implementation.

Optimization of blood pressure-lowering medication and weight loss are associated with significant reductions in both systolic and diastolic blood pressure [15]. In the present audit, diastolic blood pressure was well managed with over three-quarters of patients reaching targets of $<85 \mathrm{mmHg}$. Patients with CHD had lower DBP compared to those without CHD. This was more than likely due to the fact that those patients diagnosed as having CHD were already prescribed anti-hypertensive medication prior to their initial clinic visit. Despite good diastolic blood pressure control, systolic blood pressure control was disappointing with just over one-third achieving targets of $<130 \mathrm{mmHg}$. This may reflect ongoing white coat effects at clinic visits, despite underlying blood pressure improvements [16]. Hence, the main focus in clinics had been usage of $24 \mathrm{~h}$ blood pressure monitoring. These results are similar to the findings of the latest EUROASPIRE study which recorded that only $39 \%$ of patients achieved BP targets of $140 / 80$ and $130 / 80 \mathrm{mmHg}$ in patients with diabetes [6]. Assessing the cardiovascular risk factors as a whole and implementing earlier pharmacological and weight loss interventions before patients reach a hypertensive state could help manage the increasing burden of systolic blood pressure [17].

In the present study, despite the availability of smoking cessation treatments, one-fifth of patients continued smoking. Previous studies have shown that smoking cessation reduces the likelihood of recurrent cardiovascular events in patients with coronary heart disease [18]. However, quitting smoking is physiologically and psychologically very challenging and many patients are not suitable for pharmacologic smoking cessation intervention due to history of anxiety and depression. More "holistic-type" programs not using pharmacological intervention have reported significant improvements in smoking cessation. Therefore, a dedicated smoking cessation program in conjunction with the risk factor clinic may be warranted [19].

Obesity has been shown to have a negative impact on other cardiovascular risk factors including dyslipidemia, raised blood pressure and type II diabetes [20]. Weight loss is associated with improvements in blood pressure, total cholesterol, LDLc, triglycerides, glucose and HDLc. Therefore, weight loss is critical for reducing the cardiovascular risk profile of obese patients [20]. Over half of the patients attending the clinic were obese, significantly but not surprisingly higher than the Irish population average of $25 \%$ [22]. These findings are similar to that of the latest EUROASPIRE where $83 \%$ of patients had a BMI $\geq 25 \mathrm{~kg} / \mathrm{m}^{2}$ and $38 \%$ had $\geq 30 \mathrm{~kg} / \mathrm{m}^{2}$. Significant improvements in BMI were not observed in those without CHD. However, weights actually increased in those with CHD during clinic visits. This may be due to an initial change in patients' weight once CHD was diagnosed and a relaxation or refocus once other risk factor management was in place.

Previous studies that have adopted intense exercise interventions have been successful [20]. Drug interventions to achieve weight loss may have adverse side effects with only modest effects on weight loss and therefore were not considered as a first-line treatment for obese patients at our clinic [23]. Current medical focus is placed more on the management of the complications of obesity such as hypertension, dyslipidemia and diabetes rather than the source of many of these problems which is obesity itself. In clinical practice, cardiovascular risk factors governed by lifestyle such as smoking, BMI and waist circumference are the most difficult to manage.

In summary, our retrospective audit highlights many successes and a number of apparent failures. Some explanations for both have been considered. It is particularly important to note that in modern clinical practice with the increasing awareness about cardiovascular risk factors, the best results occur in the community. Patients whose risk factors are well controlled rarely reach the hospital risk factor clinic. Thus, this audit pertains to the patients who were not "cherry picked" for success. As observed in other studies, the cardiovascular risk factors that were managed primarily through medications were better controlled than those primarily improved by lifestyle changes. More emphasis needs to be placed on weight reduction and smoking cessation therapies, as successful management of these risk factors have been shown to lead to improvements in the other cardiovascular risk factors. The 
EUROACTION preventative cardiology program shows that with a professional, comprehensive and multidisciplinary program, lifestyle changes can be achieved leading to weight loss, reduced central obesity, reduced blood pressure and improved blood cholesterol concentrations. Barriers to prevention programs such as these include lack of time, prescribing costs and poor patient compliance. However, the feasibility of such programs should be further explored as they address the risk factors most clinicians find difficult to manage.

Acknowledgments This audit was funded by a generous grant from Merck, Sharp and Dohme Ireland without whom this audit would not have been possible.

Conflict of interest None.

\section{References}

1. Verschuren WM, Jacobs DR, Bloemberg BP et al (1995) Serum total cholesterol and long-term coronary heart disease mortality in different cultures: twenty-five year follow-up of the Seven Countries Study. JAMA 274:131-136

2. MacMahon S, Peto R, Cutler J et al (1990) Blood pressure, stroke, and coronary heart disease, I: prolonged differences in blood pressure: prospective observational studies corrected for the regression dilution bias. Lancet 335:765-774

3. Stamler J, Vaccaro O, Neaton JD et al (1993) Diabetes, other risk factors, and 12-year cardiovascular mortality for men screened in the Multiple Risk Factor Intervention Trial. Diabetes Care 16:434-444

4. (1990) The health benefits of smoking cessation: a report of the surgeon general. Md: US dept of health and human services. DHHS publication (CDC), Rockville, pp 90-8416

5. Canoy D, Boekholdt SM, Wareham N et al (2007) Body fat distribution and risk of coronary heart disease in men and women in the European Prospective Investigation into Cancer and Nutrition in Norfolk cohort. A population-based prospective study. Circulation published online, doi: 10.1161/CIRCULA TIONAHA.106.673756

6. Kotseva K, Wood D, De Backer G et al (2009) Cardiovascular prevention guidelines in daily practice: a comparison of EUROASPIRE I, II, and III surveys in eight European countries. Lancet 373:929-940

7. Warnick GR, Knopp RH, Branson L et al (1990) Estimating lowdensity lipoprotein cholesterol by the Friedewald equation is adequate for classifying patients on the basis of nationally recommended cutpoints. Clin Chem 36(1):15-19

8. Waters DD, Brotons C, Chiang CW et al (2009) Lipid treatment assessment project 2 investigators. Lipid treatment assessment project 2: a multinational survey to evaluate the proportion of patients achieving low-density lipoprotein cholesterol goals. Circulation 120(1):28-34 Epub 2009 Jun 22

9. Karalis DG, Subramanya RD, Hessen SE et al (2011) Achieving optimal lipid goals in patients with coronary artery disease. Am J Cardiol 107(6):886-890 Epub 2011 Jan 19

10. Euroaspire, II study group (2001) Lifestyle and risk factor management and use of drug therapies in coronary patients from 15 countries; principal results from EUROASPIRE II Euro Heart Survey Programme. Eur Heart J 22:554-572

11. Hausenloy DJ, Yellon DM (2008) Targeting residual cardiovascular risk: raising high-density lipoprotein cholesterol levels. Heart 94:706-714

12. Sviridov D, Nestel P, Watts G (2007) Statins and metabolism of high density lipoprotein. Cardiovasc Hematol Ag Med Chem 5:215-221

13. Nicholls SJ (2012) The AIM-HIGH (Atherothrombosis Intervention in Metabolic Syndrome with Low HDL/High Triglycerides: impact on global health outcomes) trial: to believe or not to believe? J Am Coll Cardiol 59(23):2065-2067

14. Chapman JM, Ginsberg HN, Amarenco P et al. Triglyceride-rich lipoproteins and high-density lipoprotein cholesterol in patients at high risk of cardiovascular disease: evidence and guidance for management. Eur Heart J doi:10.1093/eurheartj/ehr112

15. Schotte DE, Stunkard AJ (1990) The effects of weight reduction on blood pressure in 301 obese patients. Arch Intern Med 150(8): 1701-1704

16. Myers MG, Godwin M, Dawes M et al (2011) Conventional versus automated measurement of blood pressure in primary care patients with systolic hypertension: randomised parallel design controlled trial. BMJ 7(342):d286. doi:10.1136/bmj.d286

17. Law M, Wald N, Morris J (2003) Lowering blood pressure to prevent myocardial infarction and stroke: a new preventive strategy. Health Technol Assess 7(31):1-94

18. Aberg A, Bergstrand R, Johansson S et al (1983) Cessation of smoking after myocardial infarction: effects on mortality after 10 years. BR Heart J 49:416-422

19. Secades-Villa R, Alonso-Perez F, Garcia-Rodriguez $O$ et al (2009) Effectiveness of three intensities of smoking cessation treatment in primary care. Psychol Rep 105:747-758

20. Klein S, Lora E, Burke RN et al (2004) Clinical implications of obesity with specific focus on cardiovascular disease: a statement for professionals from the American Heart Association Council on Nutrition, Physical Activity, and Metabolism. Circulation 110:2952-2967

21. Pagotto U, Vanuzzo D, Vicennati V et al (2008) Pharmacological therapy of obesity. G Ital Cardiol 9(4 Suppl 1):83S-93S

22. Ward M, McGee H, Morgan K et al (2007) SLÁN 2007: Survey of Lifestyle, Attitudes and Nutrition in Ireland. One Island-One Lifestyle? Health and lifestyles in the Republic of Ireland and Northern Ireland: comparing the population surveys SLÁN 2007 and NIHSWS 2005. Department of Health and Children. The Stationery Office, Dublin

23. Padwal RS, Rucker D, Li SK et al (2003) Long-term pharmacotherapy for obesity and overweight. Cochrane Database Syst Rev 4 Art. No: CD004094. doi: 10.1002/14651858.CD004094. pub2

\begin{tabular}{l|lll|} 
Journal : Large 11845 & Dispatch : 17-4-2013 & Pages : $\mathbf{6}$ \\
Article No. : 954 & $\square$ & $\square$ TY & $\checkmark$ TYSESET \\
MS Code : IJMS-D-12-01969 & $\sim_{\text {CP }}$ & $\checkmark$ DISK \\
\hline
\end{tabular}

